\section{BMJ Open Respiratory Research}

\title{
High-flow nasal cannula therapy in a predominantly African American population with COVID-19 associated acute respiratory failure
}

\author{
Paul L Nguyen (D) , ${ }^{1}$ Heba Osman, ${ }^{2}$ Donovan Watza, ${ }^{1}$ Suman Khicher, ${ }^{1}$ \\ Aditi Sharma, ${ }^{1}$ Greg Dyson, ${ }^{3}$ Ghulam Saydain, ${ }^{4}$ Ayman Soubani ${ }^{4}$
}

To cite: Nguyen PL, Osman $\mathrm{H}$, Watza D, et al. High-flow nasal cannula therapy in a predominantly African American population with COVID-19 associated acute respiratory failure. BMJ Open Resp Res 2021;8:e000875. doi:10.1136/ bmjresp-2021-000875

- Additional supplemental material is published online only. To view, please visit the journal online (http://dx.doi. org/10.1136/bmjresp-2021000875).

PLN, HO and DW contributed equally.

Received 12 January 2021 Accepted 7 August 2021

Check for updates

\section{(C) Author(s) (or their} employer(s)) 2021. Re-use permitted under CC BY-NC. No commercial re-use. See rights and permissions. Published by BMJ.

For numbered affiliations see end of article.

Correspondence to Dr Paul L Nguyen; pnguye@med.wayne.edu

\section{ABSTRACT}

Importance Use of non-invasive respiratory modalities in COVID-19 has the potential to reduce rates of intubation and mortality in severe disease however data regarding the use of high-flow nasal cannula (HFNC) in this population is limited.

Objective To interrogate clinical and laboratory features of SARS-CoV-2 infection associated with high-flow failure. Design We conducted a retrospective cohort study to evaluate characteristics of high-flow therapy use early in the pandemic and interrogate factors associated with respiratory therapy failure.

Setting Multisite single centre hospital system within the metropolitan Detroit region.

Participants Patients from within the Detroit Medical Center ( $n=104,89 \%$ African American) who received HFNC therapy during a COVID-19 admission between March and May of 2020.

Primary outcome HFNC failure is defined as death or intubation while on therapy.

Results Therapy failure occurred in $57 \%$ of the patient population, factors significantly associated with failure centred around markers of multiorgan failure including hepatic dysfunction/transaminitis $(\mathrm{OR}=6.1,95 \% \mathrm{Cl} 1.9$ to $19.4, \mathrm{p}<0.01)$, kidney injury $(\mathrm{OR}=7.0,95 \% \mathrm{Cl} 2.7$ to 17.8 , $\mathrm{p}<0.01)$ and coagulation dysfunction $(\mathrm{OR}=4.5,95 \% \mathrm{Cl}$ 1.2 to $17.1, p=0.03)$. Conversely, comorbidities, admission characteristics, early oxygen requirements and evaluation just prior to HFNC therapy initiation were not significantly associated with success or failure of therapy.

Conclusions In a population disproportionately affected by COVID-19, we present key indicators of likely HFNC failure and highlight a patient population in which aggressive monitoring and intervention are warranted.

\section{INTRODUCTION}

COVID-19, a virus outbreak caused by the novel Coronavirus SARS-CoV-2, first appeared in Wuhan, China and was declared a pandemic by the WHO in March 2020. ${ }^{1}$ As of 6 December 2020, the COVID-19 pandemic has resulted in over 66 million total cases worldwide and over 1.5 million deaths in the world. ${ }^{2}$ A report from the Chinese Center for Disease Control

\section{Key messages}

Question: What are the clinical and laboratory features of SARS-CoV-2 associated with high-flow nasal cannula (HFNC) therapy failure?

Bottom line: Few characteristics, primarily laboratory measures of multiorgan failure, were significantly associated with HFNC therapy failure in an African American urban population early in the pandemic.

- Why read on: In a population disproportionately affected by COVID-19, we present key indicators of likely HFNC failure and highlight a patient population in which aggressive monitoring and intervention are warranted.

and Prevention reported approximately $14 \%$ of COVID-19 cases were classified as severe, resulting in dyspnoea, hypoxaemia, lung infiltrates $>50 \%$ within $24-48$ hours, or partial pressure of arterial oxygenation/fraction of inspired oxygen $\left(\mathrm{PaO}_{2} / \mathrm{FiO}_{2}\right)$ ratio $<300 .{ }^{3}$ Patients with COVID-19 with severe features are at significant risk for acute respiratory distress syndrome (ARDS) manifesting shortly after the onset of dyspnoea. Furthermore, increasing evidence has revealed that the COVID-19 pandemic has had a disparate impact on people of colour. ${ }^{45}$ Millett et al found while only $20 \%$ of US counties contain a majority of black Americans, they comprise $52 \%$ of all COVID-19 diagnoses and $58 \%$ of all COVID-19 deaths across the nation. ${ }^{4}$

In patients with severe hypoxia, it may be necessary to escalate treatment to invasive mechanical ventilation (MV). However, MV is associated with various adverse events such as barotrauma, pneumonia and sepsis. ${ }^{6}$ In patients who do not require immediate ventilatory support, non-invasive ventilation modalities may be used rather than proceeding directly to intubation. Standard non-invasive oxygen therapies have significant limitations 
including limitation of oxygen supply to a maximum of $15 \mathrm{~L} / \mathrm{min}$, imprecision regarding the exact amount of $\mathrm{FiO}_{2}$ delivered, and poor tolerance of both the facemask and oxygen due to inadequate heating and humidification. High-flow nasal cannula (HFNC) is an alternative oxygen modality, that has gained considerable interest as a non-invasive method of delivering substantial oxygenation to severely hypoxic patients specifically in COVID19..$^{8-12}$ Additionally, it is often better tolerated as patients report better comfort with HFNC than with standard oxygen therapy. ${ }^{13-15}$

Over the years, HFNC has gained interest due to its effectiveness in improving oxygenation, being reported to prevent the need for intubation when compared with conventional oxygen therapy without impacting mortality ${ }^{16-19}$ In 2017, a meta-analysis of six randomised controlled trials (RCTs) $(n=1892)$ reported that the intubation rate with HFNC oxygen therapy was lower than the rate with conventional oxygen therapy. ${ }^{20}$ Another meta-analysis of 18 trials, which included all published trials containing superiority tests with conventional oxygen therapy or non-inferiority tests with non-invasive positive pressure ventilation (NIPPV), reported similar positive findings but found no difference in the length of intensive care unit (ICU) stays when compared with conventional oxygen therapies or NIPPV. ${ }^{21}$ In 2019, a meta-analysis of nine randomised controlled trials and 2093 participants, published by Rochwerg and colleagues, found significantly decreased risk of intubation or oxygen therapy escalation in patients with acute hypoxic respiratory failure treated with HFNC. ${ }^{16}$ However, no difference in mortality, ICU length of stay or hospital length of stay was observed.

Although HFNC is proven effective, there are conflicting recommendations regarding the use of HFNC in patients with COVID-19 $9^{22}$ and many institutions are reluctant to use this modality in patients with COVID-19 due to risk of aerosolisation; although, evidence supporting the increased pathogen dispersal is sparse. ${ }^{24}$ Despite the potential usefulness, the utility of HFNC in patients with COVID-19 has only been studied sparsely, ${ }^{9-12} 2526$ thus the availability of data of use of HFNC in hospitalised patients with COVID-19 is limited but greatly needed. As Detroit was a major outbreak centre early in the COVID-19 pandemic, experienced significant disparities and mortality, and given the use of HFNC at our institution, we investigated characteristics of the use and failure of HFNC in a primarily African American population disproportionately affected by SARS-CoV-2.

\section{METHODS}

\section{Patient and public involvement statement}

No public involvement was involved in the design, or conduct, or reporting, or dissemination plans of this retrospective cohort study.

\section{Study design}

We conducted a retrospective cohort study within the Detroit Medical Center that includes the following hospital sites, Detroit Receiving Hospital, Harper-Hutzel University Hospital and Sinai-Grace Hospital.

Three hundred and forty-five patients were initially identified as candidates for this study as ascertained via an institutional HFNC billing list dating between 1 March 2020 and 20 May 2020. Patients were eligible for inclusion for the study if they were (1) placed on HFNC with settings of at least $20 \mathrm{~L} / \mathrm{min}$ during their hospital admission, (2) a person under investigation and/or a positive SARS-CoV-2 PCR and (3) at least 18 years of age (figure 1). Participants $(\mathrm{n}=104)$ were enrolled from the following Detroit Medical Center facilities, Detroit Receiving Hospital $(n=40)$, Harper-Hutzel University Hospital (n=41) and Sinai-Grace Hospital (n=23).

\section{Data acquisition}

Variables of interest included age, sex, race, body massindex (BMI), comorbid medical conditions, admission characteristics including laboratory data if collected within 48 hours of admission such as inflammatory markers and others, hospital course characteristics such as treatments received and measures of organ dysfunction, and outcomes data via medical record abstraction.

Admission characteristics included $\mathrm{SpO}_{2}$, administered $\mathrm{FiO}_{2}$, inflammatory laboratory markers $\mathrm{C}$ reactive protein (CRP), lactate dehydrogenase (LDH), ferritin, creatine phosphokinase and other laboratory markers, creatine, absolute lymphocyte count, D-dimer, troponin, leucocyte count, activated prothrombin time, prothrombin time, international normalised ratio (INR). We also collected admission radiographic findings on chest X-ray based on the radiological reading and separated into three classifications, normal, focal or multifocal.

Hospital course characteristics included blood and respiratory cultures if available during the admission, treatments received including use of anticoagulation, laboratory measure of organ dysfunction measured as the worst laboratory value for each patient throughout the admission for kidney injury (creatine), cardiac injury (troponin), measures of hepatic injury (alanine transaminase (ALT) and aspartate transaminase (AST)) and coagulopathy (INR). Definitions of laboratory measures of organ dysfunction were decided on a priori and based on elevations both above the standard laboratory reference range as well as what was deemed clinically significantly elevated. Hepatic injury/significant transaminitis was defined as either an elevation of ALT or AST $\geq 100$ units/L. Troponemia was defined as an elevation of troponin $\geq 100 \mathrm{ng} / \mathrm{L}$. Renal dysfunction was defined as an elevation of creatine of $\geq 2 \mathrm{mg} / \mathrm{L}$. INR dysfunction was defined as an elevation of the INR $\geq 1$.4.

Outcome variables were defined as follows: (1) HFNC failure: intubation or death while on HFNC therapy excluding patients placed into hospice care or made 'do 


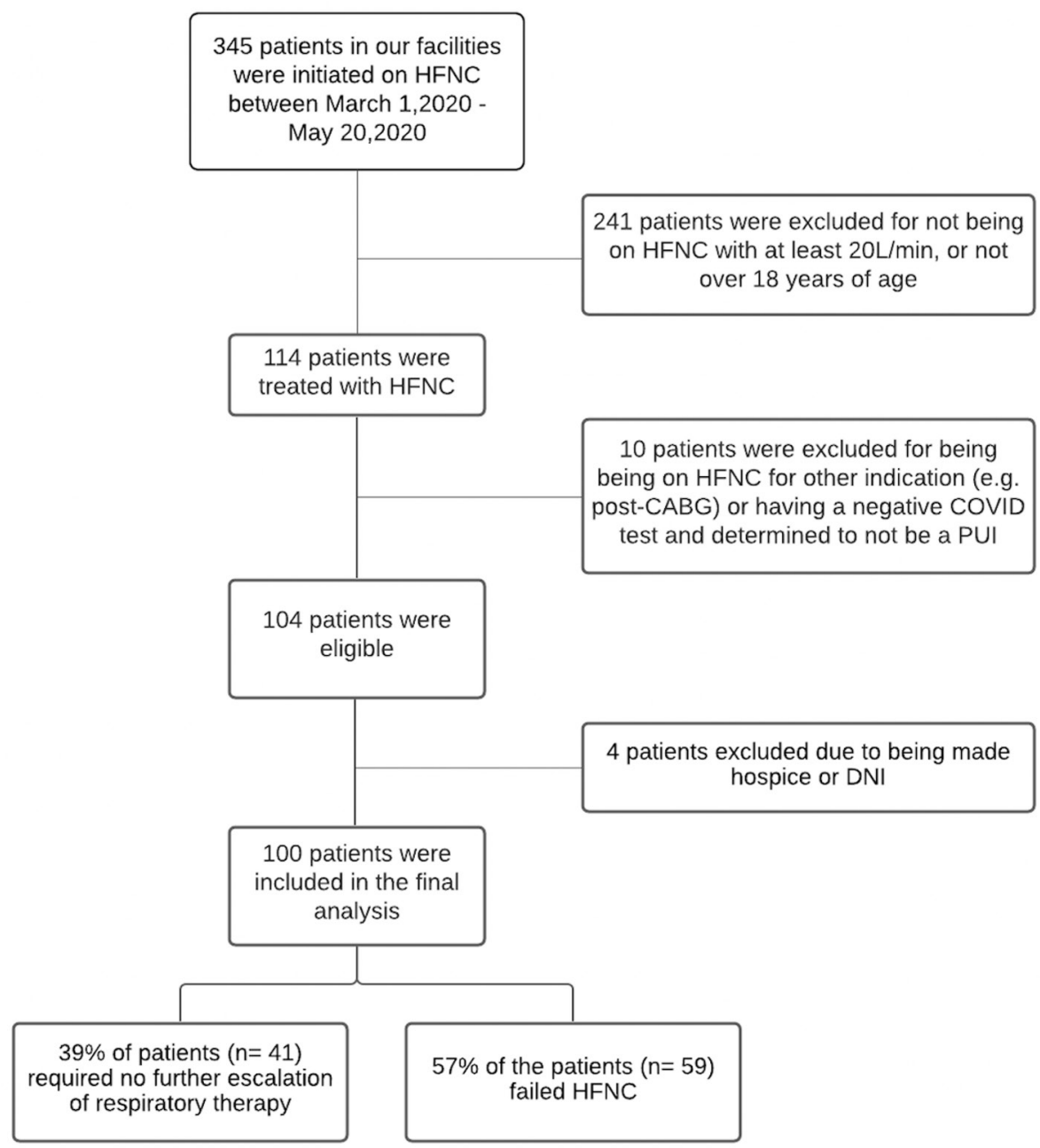

Figure 1 Study schema. DNI, do not intubate; HFNC, high-flow nasal cannula; PUI, person under investigation; CABG, coronary artery bypass graft.

not intubate' (DNI) while on HFNC, (2) ICU admission, (3) 60-day inpatient outcomes defined as discharged, remained inpatient, death or hospice/DNI. HFNC failure did not include transition to positive airway pressure (PAP) as PAP was not used during the time of this study due to initial concerns of aerosolisation risk early in the pandemic. ${ }^{27}$ Ventilator free days, measured at 28 days post-admission, is a composite outcome defined as the number of days a patient was intubation free after extubation and penalising patients who had an inpatient mortality event or who were not successfully extubated with a value of zero ventilator free days. ${ }^{28}$ Patients who were not intubated during their admission received 28 ventilator free days.

\section{Statistical analysis}

All statistical analyses were performed in R V.4.0.3 (10 October 2020). Patient characteristics and laboratory values were reported as medians and SD to limit the impact of outlier values. Primary outcomes analyses were performed using univariate logistic regression, reported as ORs with $95 \%$ CIs and two-sided $\mathrm{p}$ values, and plotted using the forestplot package in R. Multivariable effect estimates were estimated using logistic regression adjusted for relevant variables assessed at time of admission including age, gender, $\mathrm{BMI}$ and $\mathrm{SpO}_{2} / \mathrm{FiO}_{2}$ ratio. Elastic net regression was used to determine the combination of features from those with at least a modest univariate association $(\mathrm{p}<0.20)$ that were most informative and parsimonious in multivariable logistic regression predicting highflow therapy failure using the glmnet package in R.

\section{RESULTS}

One hundred and four patients were identified between March and May having been placed on HFNC for a corresponding SARS-CoV-2 diagnosis (table 1). Of these, the majority of patients were black $(88.5 \%)$, male $(58 \%)$ and older with a median age of 67 and SD of 15 years. Comorbidities were highly prevalent among these individuals, $48 \%$ with a history of obesity, $75 \%$ with a history of hypertension, $34 \%$ with a history of diabetes, $24 \%$ with a history of chronic kidney disease (CKD), $28 \%$ with a 


\begin{tabular}{|c|c|}
\hline Eligible patients (n) & 104 \\
\hline Age (median \pm SD) & $67 \pm 14.8$ \\
\hline \multicolumn{2}{|l|}{ Race } \\
\hline Black (n, \%) & $92(88.5 \%)$ \\
\hline White (n, \%) & $4(3.8 \%)$ \\
\hline Other (n, \%) & $8(7.7 \%)$ \\
\hline \multicolumn{2}{|l|}{ Gender } \\
\hline Male (n, \%) & $60(57.7 \%)$ \\
\hline Female (n, \%) & $44(42.3 \%)$ \\
\hline \multicolumn{2}{|l|}{ Body mass index } \\
\hline$<18.5(n, \%)$ & $3(2.9 \%)$ \\
\hline $18.5-24.9(n, \%)$ & $19(18.3 \%)$ \\
\hline $25-29.9(n, \%)$ & $30(28.8 \%)$ \\
\hline 30-39.9 (n, \%) & $34(32.7 \%)$ \\
\hline$>40(\mathrm{n}, \%)$ & $16(15.4 \%)$ \\
\hline Unknown & $2(1.9 \%)$ \\
\hline \multicolumn{2}{|l|}{ Medical history } \\
\hline Hypertension (n, \%) & $78(75.0 \%)$ \\
\hline Diabetes (n, \%) & $35(33.7 \%)$ \\
\hline Chronic kidney disease (n, \%) & $25(24.0 \%)$ \\
\hline Lung disease (n, \%) & $29(27.9 \%)$ \\
\hline On home oxygen $(\mathrm{n}, \%)$ & $9(8.7 \%)$ \\
\hline Heart disease $(n, \%)$ & $35(33.7 \%)$ \\
\hline Oncological (n, \%) & $7(6.7 \%)$ \\
\hline \multicolumn{2}{|l|}{ Admission labs } \\
\hline SARS-CoV-2 lab confirmed ( $n, \%)$ & $89(83.2 \%)$ \\
\hline $\mathrm{SpO}_{2} \%$ (median $\pm \mathrm{SD}$ ) & $93 \% \pm 10.7 \%$ \\
\hline $\mathrm{CRP}-\mathrm{mg} / \mathrm{L}($ median $\pm \mathrm{SD})$ & $156 \pm 112$ \\
\hline $\mathrm{CPK}$-units $/ \mathrm{L}$ (median $\pm \mathrm{SD}$ ) & $243 \pm 859$ \\
\hline LDH-units/L (median \pm SD) & $519 \pm 481$ \\
\hline Ferritin $-\mathrm{ng} / \mathrm{mL}$ (median $\pm \mathrm{SD}$ ) & $719 \pm 1594$ \\
\hline Troponin $-\mathrm{ng} / \mathrm{L}($ median $\pm \mathrm{SD})$ & $34 \pm 597.6$ \\
\hline Leucocyte count-10^9/L (median \pm SD) & $8950 \pm 5000$ \\
\hline Lymphocyte count $-10^{\wedge} 9 / \mathrm{L}($ median $\pm \mathrm{SD})$ & $0.9 \pm 0.51$ \\
\hline D-dimer-mg/L (median $\pm S D)$ & $2.0 \pm 12.8$ \\
\hline $\mathrm{PTT}-\mathrm{s}($ median $\pm \mathrm{SD})$ & $30.8 \pm 20.5$ \\
\hline PT $-\mathrm{s}($ median \pm SD) & $11.5 \pm 11.4$ \\
\hline INR (median \pm SD) & $1.1 \pm 1.3$ \\
\hline \multicolumn{2}{|l|}{ Radiographic pulmonary findings } \\
\hline Multifocal infiltrates (n, \%) & $85(81.7 \%)$ \\
\hline Focal infiltrates (n, \%) & $10(9.6 \%)$ \\
\hline Normal (n, \%) & $8(7.7 \%)$ \\
\hline
\end{tabular}

CPK, creatine phosphokinase; CRP, C reactive protein; INR, international normalised ratio; LDH, lactate dehydrogenase; PT, prothrombin time; PTT

, partial thromboplastin time history of lung disease and 34\% with a history of heart disease.

Eighty-three percent of patients had a laboratory confirmed SARS-CoV-2 infection, with $17 \%$ testing negative and clinically treated for COVID-19 given their high clinical suspicion and lack of an alternative diagnosis. On admission to the hospital, $28 \%$ of patients were found to be initially hypoxic with an $\mathrm{SpO}_{2}$ less than $88 \%$ whereas the median $\mathrm{SpO}_{2}$ for all patients on admission was $93 \%$ with an SD of $11 \%$ (table 1). Among these patients, acute phase reactants were significantly elevated in a majority of patients on admission: $71 \%$ of patients demonstrated CRP levels greater than $100 \mathrm{mg} / \mathrm{L}, 66 \%$ with $\mathrm{LDH}$ levels greater than $400 \mathrm{U} / \mathrm{L}$ and $73 \%$ with ferritin levels greater than $400 \mathrm{ng} / \mathrm{mL}$. Likewise, $86 \%$ of patients demonstrated a positive D-dimer and 59\% of patients demonstrated lymphopenia on admission. Radiographic studies on admission revealed multifocal pulmonary infiltrates in $82 \%$ of these patients and focal infiltrates in an additional $10 \%$ of patients.

Throughout the hospital course, patients often developed extra-pulmonary organ dysfunction (table 2). Most common among these was kidney dysfunction, with $80 \%$ of patients with no history of CKD developing a rise in creatine of greater than $1.1 \mathrm{mg} / \mathrm{dL}$ and $65 \%$ of the study population developing kidney injury defined as a creatine greater than $2.0 \mathrm{mg} / \mathrm{dL}$. Additional measures of organ dysfunction include hepatic injury (transaminitis $>100$ ) in $28 \%$ of patients, cardiac injury (troponin $>100$ ) in $31 \%$ of patients and coagulation dysfunction (INR $>2$ ) in $11 \%$ of patients. When looking at secondary infections, a proportion of patients also went on to develop bacteraemia during their admission with $13.5 \%$ of patients developing positive blood cultures after excluding those with likely skin contamination. For respiratory cultures, approximately $25 \%$ of patients were found to have positive growth and notable among these were Pseudomonas $(7 / 26)$ and Staphylococcus $(3 / 26)$ species.

As these patients were admitted between March and May 2020, a majority of patients were placed on hydroxychloroquine $(78.8 \%)$ and/or steroids $(73.1 \%)$ during their COVID-19 admission. Use of anticoagulants among these patients varied with $43 \%$ receiving prophylaxis dosing, $45 \%$ receiving therapeutic dosing and $12 \%$ receiving no anticoagulation therapy. From an outcomes perspective, the median hospital stay was 16 days with a wide SD of 15.6 days. Initiation of HFNC among patients with SARS-CoV-2 occurred in the setting of the emergency department, general medical floor or ICU. Of those requiring HFNC therapy, $76 \%$ of patients were admitted to the ICU with a median length of stay of 9 days. Additionally, $58 \%$ required eventual intubation with a median duration of 8 days. At 60 days, only $37 \%$ were discharged from the hospital whereas $53 \%$ suffered an inpatient mortality event with an additional $8 \%$ being placed on hospice.

Prior to HFNC initiation, patients were on average hospitalised for 4 days. Approximately half of all patients 


\begin{tabular}{|c|c|}
\hline \multicolumn{2}{|l|}{ Indicators of organ dysfunction } \\
\hline Creatin $-\mathrm{mg} / \mathrm{dL}($ median $\pm \mathrm{SD}$ ) & $3.7 \pm 3.9$ \\
\hline Kidney injury (Cre >2.0, n, \%) & $68(65 \%)$ \\
\hline ALT-units/L (median $\pm S D$ ) & $29 \pm 861$ \\
\hline AST-units/L (median \pm SD) & $52 \pm 1097$ \\
\hline Hepatic injury (LFTs>100, n, \%) & $29(28 \%)$ \\
\hline Troponin - ng/L (median $\pm S D$ ) & $65 \pm 2760$ \\
\hline Cardiac injury (trop >100, n, \%) & $32(31 \%)$ \\
\hline PT $-\mathrm{s}$ (median $\pm \mathrm{SD}$ ) & $12.0 \pm 14.9$ \\
\hline INR (median $\pm \mathrm{SD}$ ) & $1.17 \pm 1.64$ \\
\hline Coagulation dysfunction (INR >2, n, \%) & $11(11 \%)$ \\
\hline \multicolumn{2}{|l|}{ Cultures } \\
\hline Positive blood cultures (n, \%) & $14(13.5 \%)$ \\
\hline Not obtained (n, \%) & $9(8.7 \%)$ \\
\hline Positive respiratory cultures (n, \%) & $26(25.0 \%)$ \\
\hline Not obtained (n, \%) & $47(45.2 \%)$ \\
\hline Staphylococcus aureus (n, \%) & $3(2.9 \%)$ \\
\hline Pseudomonas aeruginosa (n, \%) & $7(6.7 \%)$ \\
\hline \multicolumn{2}{|l|}{ Treatments received } \\
\hline Hydroxychloroquine (n, \%) & $82(78.8 \%)$ \\
\hline Steroids (n, \%) & $76(73.1 \%)$ \\
\hline IL-6 inhibitor (n, \%) & $5(4.8 \%)$ \\
\hline Convalescent plasma (n, \%) & $0(0 \%)$ \\
\hline $\operatorname{ECMO}(n, \%)$ & $4(3.8 \%)$ \\
\hline \multicolumn{2}{|l|}{ Anticoagulation } \\
\hline DVT prophylaxis dosing (n, \%) & $45(43.3 \%)$ \\
\hline Therapeutic (n, \%) & $47(45.2 \%)$ \\
\hline None (n, \%) & $12(11.5 \%)$ \\
\hline \multicolumn{2}{|l|}{ Outcomes } \\
\hline Hospital length of stay (days, median $\pm S D$ ) & $16 \pm 15.6$ \\
\hline ICU admission (n, \%) & $79(76.0 \%)$ \\
\hline ICU length of stay (days, median $\pm S D$ ) ${ }^{*}$ & $9.0 \pm 16.1$ \\
\hline Required intubation (n, \%) & $62(57.9 \%)$ \\
\hline Length of intubation (days, median $\pm \mathrm{SD}$ ) $\dagger$ & $8.0 \pm 10.8$ \\
\hline Ventilator free days at 28 days (median $\pm S D$ ) & $0.0 \pm 12.3$ \\
\hline \multicolumn{2}{|l|}{ Outcome at 60 days } \\
\hline Discharged (n, \%) & $38(36.5 \%)$ \\
\hline Remained inpatient (n, \%) & $3(2.9 \%)$ \\
\hline Hospice (n, \%) & $8(7.7 \%)$ \\
\hline Deceased (n, \%) & $55(52.8 \%)$ \\
\hline Readmission within 30 days (n, \%) & $6(5.7 \%)$ \\
\hline
\end{tabular}

*Among individuals admitted to the ICU.

†Among individuals requiring intubation.

ALT, alanine transaminase

; AST, aspartate transaminase

; DVT, deep vein thrombosis

; ECMO, extracorporeal membrane oxygenation

; ICU, intensive care unit; IL-6, interleukin 6; INR, international normalised ratio; LFT, liver function tests

; PT, prothrombin time. received an arterial blood gas (ABG) prior to initiation, with the median demonstrating a mild respiratory alkalosis with hypoxia (online supplemental table 1). Additionally, we computed a modified sequential organ failure score (mSOFA) 24 hours prior to high flow therapy with patients demonstrating a median score of 5 and SD of 2 , thus placing most patients within the lowest predicted mortality risk score category $(0-7) \cdot{ }^{29}$ On HFNC initiation, most patients were already admitted to the ICU and started with an $\mathrm{FiO}_{2}$ ranging between $85 \%$ and $100 \%$ and flow rate of $30-40 \mathrm{~L} / \mathrm{min}$ with a median duration of therapy of 2 days. Seventy-six per cent of the cohort was ultimately admitted to the ICU.

\section{Primary outcome}

To understand patient and disease factors associated with HFNC outcomes we evaluated for association with HFNC failure defined as an event resulting in intubation or mortality while on HFNC (figure 2, table 3). Failure occurred in $57 \%$ of the patient population with $39 \%$ requiring no further escalation of respiratory therapy and $4 \%$ being made hospice or DNI while on therapy and thus excluded from further analyses. Neither demographics nor medical history were significantly associated with HFNC failure. On admission evaluation, only ferritin demonstrated a modest association with HFNC failure with an approximately $11 \%$ increased odds of failure for every increase in $100 \mathrm{ng} / \mathrm{mL}$ above $300 \mathrm{ng} /$ $\mathrm{mL}(95 \%$ CI 0.98 to $1.25, \mathrm{p}=0.09)$. Oxygen requirements at admission were also not associated with HFNC failure during the hospital course. However, measures of organ dysfunction, occurring during the admission, were strongly associated with HFNC failure; transaminitis was associated with a sixfold increase in failure rate (95\% CI 1.9 to $19.4, \mathrm{p}<0.01$ ), kidney injury was associated with a sevenfold increase in failure rate (95\% CI 2.7 to $17.8, \mathrm{p}<0.01)$ and coagulation dysfunction was associated with a 41/2-fold increase in failure rate (95\% CI 1.2 to $17.1, \mathrm{p}=0.03$ ) and these associations persisted in the setting of covariable adjustment (online supplemental table 2). Additionally, patients receiving hydroxychloroquine trended towards a $2^{1 / 2}$-fold increase in failure rate with a modest statistical association (95\% CI 0.96 to $7.20, \mathrm{p}=0.06)$. Conversely, measures of arterial $\mathrm{pH}$ and $\mathrm{PaO}_{2}$ as well as mSOFA scoring immediately prior to HFNC initiation were not significantly associated with HFNC failure. Among patients who experienced HFNC failure, mortality was significantly elevated with an associated sevenfold increase in death (95\% CI 2.8 to 18.2, $\mathrm{p}<0.01)$. HFNC failure was associated with an average reduction of 16 ventilator free days when assessed at 28 days (95\% CI 11.6 to $20.2, \mathrm{p}<0.01$ ). To identify the subset of clinical and laboratory features that in combination best predicted high-flow therapy failure, elastic net logistic regression was used on features with an at least modest association with the primary outcome $(p<0.20)$. Five features remained after regularisation of high-flow 


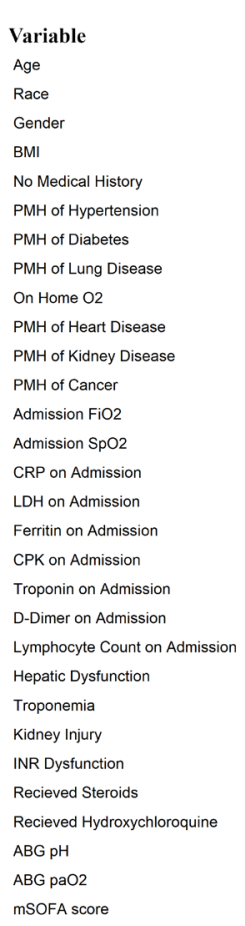

\begin{tabular}{rccc}
\multicolumn{5}{c}{ OR\% } & Lower & Upper & p value \\
0.92 & 0.7 & 1.21 & 0.53 \\
1.27 & 0.28 & 5.63 & 0.76 \\
1.26 & 0.56 & 2.81 & 0.57 \\
1.22 & 0.83 & 1.79 & 0.32 \\
1.4 & 0.12 & 16.01 & 0.78 \\
0.47 & 0.18 & 1.25 & 0.13 \\
0.89 & 0.39 & 2.05 & 0.78 \\
1.69 & 0.67 & 4.23 & 0.26 \\
1.43 & 0.34 & 6.1 & 0.63 \\
0.92 & 0.39 & 2.13 & 0.84 \\
1.53 & 0.59 & 4.02 & 0.38 \\
1.42 & 0.25 & 8.13 & 0.69 \\
1.01 & 0.9 & 1.14 & 0.83 \\
0.71 & 0.47 & 1.08 & 0.11 \\
1.00 & 0.81 & 1.22 & 0.97 \\
1.22 & 0.93 & 1.6 & 0.15 \\
1.11 & 0.99 & 1.25 & 0.09 \\
1.01 & 0.95 & 1.09 & 0.68 \\
0.97 & 0.9 & 1.05 & 0.50 \\
0.97 & 0.9 & 1.05 & 0.50 \\
1.08 & 0.49 & 2.39 & 0.84 \\
6.09 & 1.91 & 19.43 & $<0.01$ \\
2.1 & 0.82 & 5.37 & 0.12 \\
6.96 & 2.71 & 17.83 & $<0.01$ \\
4.47 & 1.17 & 17.06 & 0.03 \\
0.01 & 0.01 & 20.0 & 0.99 \\
2.64 & 0.97 & 7.2 & 0.06 \\
0.05 & 0.01 & 20.0 & 0.47 \\
0.98 & 0.96 & 1.01 & 0.24 \\
1.06 & 0.86 & 1.31 & 0.59 \\
& & & \\
\hline
\end{tabular}

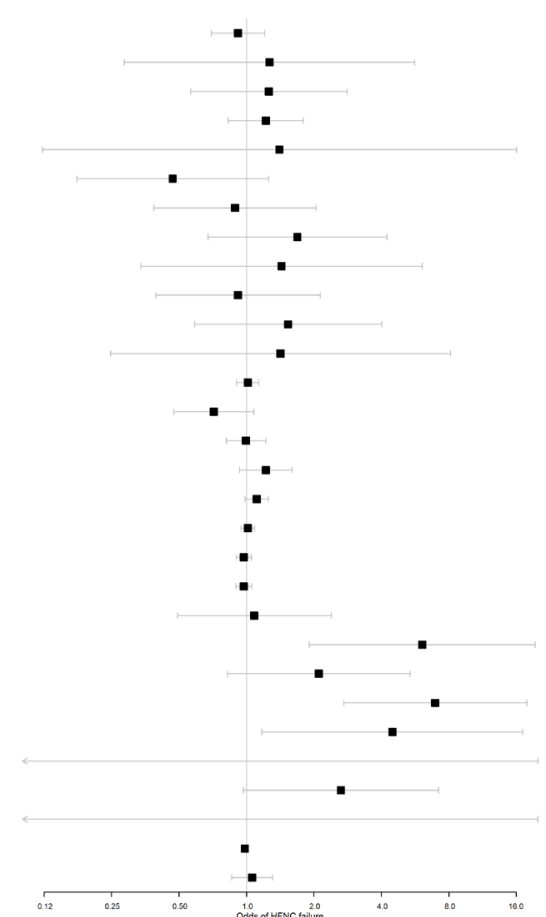

Figure 2 Associations with high-flow therapy failure. $\mathrm{PMH}$, past medical history; ABG, arterial blood gas; BMI, body mass index; CPK, creatine phosphokinase; CRP, C reactive protein; LDH, lactate dehydrogenase; INR, international normalised ratio; mSOFA, modified sequential organ failure score.

therapy failure predictors, laboratory measures of kidney $(\mathrm{OR}=7.1,95 \%$ CI 2.3 to 21.7$)$, hepatic $(\mathrm{OR}=4.5,95 \%$ CI 1.2 to 17.5$)$ and coagulation $(\mathrm{OR}=2.1,95 \%$ CI 0.44 to $10.0)$ dysfunction as well as a medical history of hypertension $(\mathrm{OR}=0.26,95 \%$ CI 0.07 to 0.94$)$ and treatment with hydroxychloroquine ( $\mathrm{OR}=4.0,95 \%$ CI 1.12 to 14.2 ) in this sample.

\section{DISCUSSION}

The COVID-19 pandemic has led to an unprecedented healthcare crisis. Patients presenting with moderate and severe SARS-CoV-2 pneumonia universally require oxygen administration, ranging from nasal cannula to MV; complicated by a widely varied disease presentation ranging from mild respiratory symptoms to cytokine storm with multisystem involvement, septic shock and severe respiratory failure. ${ }^{30}$

Presented here is to our knowledge the largest detailed investigation of the use of high flow nasal cannula in the SARS-CoV-2 pandemic in a primary African-American urban population. This sample is comprised patients admitted early during March-30 May 2020 in Detroit, USA, a first wave outbreak epicentre severely affected by COVID-19 resulting in 26409 cases and 2947 deaths in metropolitan Detroit during this period. A considerable number of these cases occurred in minority populations (estimated to be greater than $40 \%$ ), leading to a statewide initiative, the Michigan Coronavirus Task Force on Racial Disparities, to address these disparities. ${ }^{31}$ Our study reflects these observations, as our study-eligible patient population contained a considerable proportion of African American patients $(88.5 \%)$ who experienced a significantly higher burden of comorbidities that is, $76.9 \%$ with above normal BMI (overweight: $28.8 \%$, obesity: $48.1 \%$ ), followed by with hypertension $(75 \%)$, diabetes $(33.7 \%)$, heart disease $(33.7 \%)$, lung disease $(27.9 \%)$, CKD (24\%) and oncological disease $(6.7 \%)$, as well as elevated inpatient mortality $(52.8 \%)$.

We demonstrate the characteristics and outcomes of high-flow therapy for COVID-19 early in the SARS-CoV-2 pandemic in a primarily underserved urban population. Within our sample of patients, 39\% were treated with HFNC successfully and required no additional respiratory therapy escalation. These data and others support HFNC utilisation to optimise healthcare resources and potentially limit intubation in severe COVID-19 cases. A smaller study in Madrid, Spain reported similar HFNC success rates $(47.5 \%$ vs $39.4 \%)$ with a mortality rate of $22.5 \% .^{12}$ Relative to the Detroit sample, patients studied were younger, experienced less comorbidities and presented with low CURB-65 scores indicating less severe disease. With respect to monitoring of HFNC in respiratory distress syndrome, studies have shown changes in respiratory rate and $\mathrm{PaO}_{2} / \mathrm{FiO}_{2}$ as indicators of imminent failure. ${ }^{32}$ Other studies have suggested using the ROX index as a marker of HFNC failure risk in patients with ARDS. ${ }^{33}$ In our facility, intubation was guided by clinical reasoning and deteriorating respiratory status of the patient and varies from clinician to clinician. 
Table 3 Comparison of characteristics by the primary outcome

\begin{tabular}{|c|c|c|}
\hline Characteristic & $\begin{array}{l}\text { HFNC failure } \\
(\mathrm{N}=59)\end{array}$ & $\begin{array}{l}\text { HFNC } \\
\text { success } \\
(\mathrm{N}=41)\end{array}$ \\
\hline Age (median) & 66 & 68 \\
\hline \multicolumn{3}{|l|}{ Race $(\mathrm{n}, \%)$} \\
\hline African American & $50(85 \%)$ & $38(93 \%)$ \\
\hline Caucasian & $4(7 \%)$ & $0(0 \%)$ \\
\hline \multicolumn{3}{|l|}{ Gender (n, \%) } \\
\hline Male & $35(59 \%)$ & $22(54 \%)$ \\
\hline Female & $24(41 \%)$ & $19(46 \%)$ \\
\hline \multicolumn{3}{|l|}{ BMI (n, \%) } \\
\hline$<18.5$ & $1(2 \%)$ & $2(5 \%)$ \\
\hline $18.5-24.9$ & $7(12 \%)$ & $10(24 \%)$ \\
\hline $25-29.9$ & $21(36 \%)$ & $8(20 \%)$ \\
\hline $30-39.9$ & $19(32 \%)$ & $14(34 \%)$ \\
\hline$>40$ & $10(17 \%)$ & $6(15 \%)$ \\
\hline \multicolumn{3}{|l|}{ Comorbidities } \\
\hline Hypertension (n, \%) & $41(69 \%)$ & $34(83 \%)$ \\
\hline Diabetes (n, \%) & $20(34 \%)$ & $15(37 \%)$ \\
\hline Lung disease (n, \%) & $19(32 \%)$ & $9(22 \%)$ \\
\hline Heart disease (n, \%) & $19(32 \%)$ & $14(34 \%)$ \\
\hline Kidney disease (n, \%) & $16(27 \%)$ & $8(20 \%)$ \\
\hline Cancer (n, \%) & $4(7 \%)$ & $2(5 \%)$ \\
\hline \multicolumn{3}{|l|}{ Admission characteristics } \\
\hline $\mathrm{FiO}_{2}$ (median) & $21 \%$ & $21 \%$ \\
\hline $\mathrm{SpO}_{2}$ (median) & $91 \%$ & $93 \%$ \\
\hline CRP (median) & 160 & 143 \\
\hline LDH (median) & 573 & 414 \\
\hline Ferritin (median) & 693 & 744 \\
\hline CPK (median) & 233 & 249 \\
\hline Troponin (median) & 31 & 38 \\
\hline D-dimer (median) & 1.96 & 2.00 \\
\hline Lymphocyte count (median) & 900 & 900 \\
\hline \multicolumn{3}{|l|}{ Hospital course } \\
\hline Hepatic dysfunction (n, \%) & $23(39 \%)$ & $4(10 \%)$ \\
\hline Troponemia (n, \%) & $21(36 \%)$ & $9(22 \%)$ \\
\hline Kidney injury (n, \%) & $49(83 \%)$ & $18(44 \%)$ \\
\hline INR dysfunction (n, \%) & $16(27 \%)$ & $3(7 \%)$ \\
\hline Received steroids (n, \%) & $45(76 \%)$ & $29(71 \%)$ \\
\hline Received HCQ (n, \%) & $51(86 \%)$ & $29(71 \%)$ \\
\hline ABG pH prior to HFNC (median) & 7.423 & 7.428 \\
\hline ABG pO2 prior to HFNC (median) & 58.6 & 65.3 \\
\hline mSOFA prior to HFNC (median) & 5 & 5 \\
\hline Ventilator free days (mean) & 3.1 & 19.0 \\
\hline Sixty-day mortality (n, \%) & $41(69 \%)$ & $11(27)$ \\
\hline
\end{tabular}

$\mathrm{ABG}$, arterial blood gas; $\mathrm{BMI}$, body mass index; $\mathrm{CPK}$, creatine phosphokinase; CRP, C reactive protein; $\mathrm{HCQ}$, hydroxychloroquine ; HFNC, high-flow nasal cannula; INR, international normalised ratio; $\mathrm{LDH}$, lactate dehydrogenase; mSOFA, modified sequential organ failure score.
Patients also did not receive interval ABG sampling to monitor response to HFNC therapy secondary to resource and personnel shortages. Unfortunately, resource and personnel shortages were at the highest during this period of the pandemic in the Detroit medical system and healthcare provider contact with confirmed SARS-CoV-2 was limited when possible. Other such studies have similar limitations. ${ }^{25}$

In our cohort, we observed a mortality rate of $53 \%$ similar to that reported in other studies with mortality estimates ranging from $52 \%$ to $61 \% .^{34}{ }^{35}$ These data and others, ${ }^{36}{ }^{37}$ suggest HFNC use reduces intubation and subsequent MV. While these external data suggest a minimal impact on mortality, in our sample we observed a strong association of reduced mortality in individuals with COVID-19 when treated with high-flow therapy for those not requiring MV. Additional prospective studies with matched controls are necessary to determine whether this effect remains true. Mortality remains high among severe COVID-19 respiratory disease likely secondary to the complexity of the infection and development of atypical $\operatorname{ARDS}^{38}$ compounded by a higher than expected proportion of patients with hypercoagulability and multisystem involvement (hepatic, renal and cardiac injury) than reported in typical ARDS..$^{39} 40$

Interestingly, our study demonstrates that COVID-19 related multi-organ dysfunction such as hepatic dysfunction (OR 6.09, 95\% CI 1.9 to $19.4, \mathrm{p}=<0.01)$, renal dysfunction (OR 6.96, 95\% CI 2.7 to $17.8, p=<0.01$ ) and INR dysfunction (OR 4.47, 95\% CI 1.2 to $17.1, \mathrm{p}=<0.03$ ) are associated with increased risk of HFNC failure (figure 2). The presence and degree of the multisystem involvement could prove to be a useful tool to identify patients at high risk of HFNC therapy failure and thus subsequent need for MV. Additionally, there has been concern of elevated mortality in patients receiving delayed intubation during the use of HFNC and therefore, it is imperative to rapidly identify high-risk patients for monitoring and intervention. ${ }^{41}$ Further investigations should be pursued to evaluate these markers of HFNC therapy failure in additional SARS-CoV-2 populations and such studies should include an appropriate matched control group who did not receive HFNC to evaluate whether HFNC therapy differentially impacts mortality and whether markers of HFNC failure are useful prognosticators in COVID-19.

\section{LIMITATIONS}

Our study has several limitations. As this study is a single centre, retrospective cohort study that included fewer patients and no matched control group assessment of high-flow therapy association temporality and impact on intubation rate in COVID-19 was limited. Therefore, a prospective randomised controlled with larger cohorts and multi-centre analysis is needed to confirm our results. Additionally, our facility did not employ criteria such as the ROX index to aid in the identification of HFNC therapy failure and guide intubation usage. ${ }^{42}$ 
Furthermore, these patients were receiving the recommended treatment during the first wave of COVID-19 which consisted of hydroxychloroquine and steroids. As a result, this impacts the study's generalisability as the recommended treatments continue to evolve as we continue to learn more about COVID-19.

\section{Author affiliations}

${ }^{1}$ Department of Internal Medicine, Wayne State University School of Medicine, Detroit, Michigan, USA

${ }^{2}$ Department of Medicine and Pediatrics, Wayne State University School of Medicine, Detroit, Michigan, USA

${ }^{3}$ Department of Oncology, Bioinformatics and Biostatistics Core, Wayne State University School of Medicine, Detroit, Michigan, USA

${ }^{4}$ Division of Pulmonary and Critical Care, Wayne State University School of Medicine, Detroit, Michigan, USA

Contributors PLN conceptualised the study. PLN, HO, DW, SK, ASharma, GD, GS, ASoubani had substantial contributions to the acquisition, analysis, or interpretation of data for the work; PLN, HO, DW, SK, ASharma, GD, GS, ASoubani drafted the work or revised it critically for important intellectual content; PLN, HO, DW, SK, ASharma, GD, GS, ASoubani had final approval of the version to be published; PLN, HO, DW, SK, ASharma, GS, ASoubani had agreement to be accountable for all aspects of the work in ensuring that questions related to the accuracy or integrity of any part of the work are appropriately investigated and resolved.

Funding The authors have not declared a specific grant for this research from any funding agency in the public, commercial or not-for-profit sectors.

Competing interests None declared.

Patient consent for publication Not required.

Ethics approval This study was approved by both the Detroit Medical Center and Wayne State University Institutional Review Board (IRB Protocol \#20-04-2179). A waiver of consent was granted as this study was a retrospective study with minimal risk and had no patient contact.

Provenance and peer review Not commissioned; externally peer reviewed.

Data availability statement Data are available upon reasonable request and upon approvable from our institutional IRB.

Supplemental material This content has been supplied by the author(s). It has not been vetted by BMJ Publishing Group Limited (BMJ) and may not have been peer-reviewed. Any opinions or recommendations discussed are solely those of the author(s) and are not endorsed by BMJ. BMJ disclaims all liability and responsibility arising from any reliance placed on the content. Where the content includes any translated material, BMJ does not warrant the accuracy and reliability of the translations (including but not limited to local regulations, clinical guidelines, terminology, drug names and drug dosages), and is not responsible for any error and/or omissions arising from translation and adaptation or otherwise

Open access This is an open access article distributed in accordance with the Creative Commons Attribution Non Commercial (CC BY-NC 4.0) license, which permits others to distribute, remix, adapt, build upon this work non-commercially, and license their derivative works on different terms, provided the original work is properly cited, appropriate credit is given, any changes made indicated, and the use is non-commercial. See: http://creativecommons.org/licenses/by-nc/4.0/.

ORCID iD

Paul L Nguyen http://orcid.org/0000-0001-7998-293X

\section{REFERENCES}

1 WHO director-general's opening remarks at the media briefing on COVID-19, 2020. Available: https://www.who.int/director-general/ speeches/detail/who-director-general-s-opening-remarks-at-themedia-briefing-on-covid-19-11-march-2020 [Accessed 06 Dec 2020].

2 Home - johns hopkins coronavirus resource center [internet]. Available: https://coronavirus.jhu.edu/ [Accessed 06 Dec 2020].

3 Wu Z, McGoogan JM. Characteristics of and important lessons from the coronavirus disease 2019 (covid-19) outbreak in China: summary of a report of 72314 cases from the Chinese center for disease control and prevention. JAMA 2020;323:1239-42 https://pubmedncbi-nlm-nih-gov.proxy.lib.wayne.edu/32091533/
4 Millett GA, Jones AT, Benkeser D, et al. Assessing differential impacts of COVID-19 on black communities. Ann Epidemiol 2020;47:37-44 https://pubmed-ncbi-nlm-nih-gov.proxy.lib.wayne. edu/32419766

5 Whitmer - governor whitmer signs executive order creating the michigan coronavirus task force on racial disparities [Internet]. Available: https://www.michigan.gov/whitmer/0,9309,7-387-90499526478--,00.html [Accessed 21 Dec 2020].

6 Slutsky AS, Ranieri VM. Ventilator-induced lung injury. N Engl J Med Overseas Ed 2013;369:2126-36 http://www.nejm.org/doi/

7 Esteban A, Anzueto A, Frutos F, et al. Characteristics and outcomes in adult patients receiving mechanical ventilation: a 28-day international study. JAMA 2002;287:345-55 https://pubmed-ncbinlm-nih-gov.proxy.lib.wayne.edu/11790214/

8 Shoemaker MT, Pierce MR, Yoder BA, et al. High flow nasal cannula versus nasal CPAP for neonatal respiratory disease: a retrospective study. J Perinatol 2007;27:85-91 https://pubmed-ncbi-nlm-nih-gov. proxy.lib.wayne.edu/17262040/

9 He G, Han Y, Fang Q. Clinical experience of high-flow nasal cannula oxygen therapy in severe COVID-19 patients. Zhejiang Da Xue Xue Bao Yi Xue Ban [Internet] 2020;49:232-9 https://pubmed-ncbi-nlmnih-gov.proxy.lib.wayne.edu/32268019/

10 Geng S, Mei Q, Zhu C, et al. High flow nasal cannula is a good treatment option for COVID-19. Heart Lung 2020;49:444-5 https:// pubmed-ncbi-nlm-nih-gov.proxy.lib.wayne.edu/32295710/

11 Wang K, Zhao W, Li J, et al. The experience of high-flow nasal cannula in hospitalized patients with 2019 novel coronavirusinfected pneumonia in two hospitals of Chongqing, China. Ann Intensive Care 2020;10:37 https://pubmed-ncbi-nlm-nih-gov.proxy. lib.wayne.edu/32232685/

12 Panadero C, Abad-Fernández A, Rio-Ramírez Ma Teresa, et al. Highflow nasal cannula for acute respiratory distress syndrome (ARDS) due to COVID-19. Multidiscip Respir Med 2020;15 https://pubmedncbi-nlm-nih-gov.proxy.lib.wayne.edu/32983456/

13 Sztrymf B, Messika J, Mayot T, et al. Impact of high-flow nasal cannula oxygen therapy on intensive care unit patients with acute respiratory failure: a prospective observational study. J Crit Care 2012;27:324.e9-324.e13 https://pubmed-ncbi-nlm-nih-gov.proxy.lib. wayne.edu/21958974/

14 Cuquemelle E, Pham T, Papon J-F, et al. Heated and humidified high-flow oxygen therapy reduces discomfort during hypoxemic respiratory failure. Respir Care 2012;57:1571-7 https://pubmedncbi-nlm-nih-gov.proxy.lib.wayne.edu/22417569/

15 Sztrymf B, Messika J, Bertrand F, et al. Beneficial effects of humidified high flow nasal oxygen in critical care patients: a prospective pilot study. Intensive Care Med 2011;37:1780-6 https:// pubmed-ncbi-nlm-nih-gov.proxy.lib.wayne.edu/21946925/

16 Rochwerg B, Granton D, Wang DX, et al. High-flow nasal cannula compared with conventional oxygen therapy for acute hypoxemic respiratory failure: author's reply. Intensive Care Med 2019;45:1171 https://pubmed-ncbi-nlm-nih-gov.proxy.lib.wayne.edu/31236637/

17 Nagata K, Morimoto T, Fujimoto D, et al. Efficacy of high-flow nasal cannula therapy in acute hypoxemic respiratory failure: decreased use of mechanical ventilation. Respir Care 2015;60:1390-6 https:// pubmed-ncbi-nlm-nih-gov.proxy.lib.wayne.edu/26106206/

18 Thille AW, Muller G, Gacouin A, et al. Effect of postextubation high-flow nasal oxygen with noninvasive ventilation vs highflow nasal oxygen alone on reintubation among patients at high risk of extubation failure: a randomized clinical trial. JAMA 2019;322:1465-75 https://pubmed-ncbi-nlm-nih-gov.proxy.lib. wayne.edu/31577036/

19 Bocchile RLR, Cazati DC, Timenetsky KT, et al. The effects of high-flow nasal cannula on intubation and re-intubation in critically ill patients: a systematic review, meta-analysis and trial sequential analysis. Rev Bras Ter Intensiva 2018;30:487-95 https://pubmedncbi-nlm-nih-gov.proxy.lib.wayne.edu/30672973/

$20 \mathrm{Ou} X$, Hua Y, Liu J, et al. Effect of high-flow nasal cannula oxygen therapy in adults with acute hypoxemic respiratory failure: a meta-analysis of randomized controlled trials. Can Med Assoc J 2017;189:E260-7 https://pubmed-ncbi-nlm-nih-gov.proxy.lib.wayne. edu/28246239/ doi:10.1503/cmaj.160570

$21 \mathrm{Ni}$ Y-N, Luo J, Yu H, et al. Can high-flow nasal cannula reduce the rate of endotracheal intubation in adult patients with acute respiratory failure compared with conventional oxygen therapy and noninvasive positive pressure ventilation?: a systematic review and meta-analysis. Chest 2017;151:764-775-75 https://pubmedncbi-nlm-nih-gov.proxy.lib.wayne.edu/28089816/ doi:10.1016/j. chest.2017.01.004

22 Clinical management of COVID-19 [Internet]. Available: https:// www.who.int/publications//item/clinical-management-of-covid-19 [Accessed 06 Dec 2020]. 
23 Alhazzani W, Møller MH, Arabi YM, et al. Surviving sepsis campaign: guidelines on the management of critically ill adults with coronavirus disease 2019 (COVID-19). Crit Care Med 2020;48:e440-69. doi:10.1097/CCM.0000000000004363

24 Li J, Fink JB, Ehrmann S. High-flow nasal cannula for COVID-19 patients: Risk of bio-aerosol dispersion. Eur Respir J 2020;56. doi:10.1183/13993003.03136-2020. [Epub ahead of print: Available from] https://pubmed-ncbi-nlm-nih-gov.proxy.lib.wayne.edu/ 32299867/

25 Patel M, Gangemi A, Marron R, et al. Retrospective analysis of high flow nasal therapy in COVID-19-related moderate-tosevere hypoxaemic respiratory failure. BMJ Open Respir Res 2020;7:e000650 https://pubmed-ncbi-nlm-nih-gov.proxy.lib.wayne. edu/32847947/

26 Vianello A, Arcaro G, Molena B, et al. High-flow nasal cannula oxygen therapy to treat patients with hypoxemic acute respiratory failure consequent to SARS-CoV-2 infection. Thorax 2020;75:998-1000 https://pubmed-ncbi-nlm-nih-gov.proxy.lib. wayne.edu/32703883/ doi:10.1136/thoraxjnl-2020-214993

27 Miller DC, Beamer P, Billheimer D, et al. Aerosol risk with noninvasive respiratory support in patients with COVID-19. J Am Coll Emerg Physicians Open 2020;1:521-6 https://pubmed-ncbi-nlm-nih-gov. proxy.lib.wayne.edu/32838370/

28 Yehya N, Harhay MO, Curley MAQ, et al. Reappraisal of ventilatorfree days in critical care research. Am J Respir Crit Care Med 2019;200:828-36 https://pubmed-ncbi-nlm-nih-gov.proxy.lib.wayne. edu/31034248/ doi:10.1164/rccm.201810-2050CP

29 Grissom CK, Brown SM, Kuttler KG, et al. A modified sequential organ failure assessment score for critical care triage. Disaster Med Public Health Prep 2010;4:277-84 https://pubmed-ncbi-nlm-nih-gov. proxy.lib.wayne.edu/21149228/ doi:10.1001/dmp.2010.40

30 Wang D, Hu B, Hu C, et al. Clinical characteristics of 138 hospitalized patients with 2019 novel coronavirus-infected pneumonia in Wuhan, China. JAMA 2020;323:1061-9 https:// pubmed-ncbi-nlm-nih-gov.proxy.lib.wayne.edu/32031570/

31 MDHHS - coronavirus task force on racial disparities [Internet]. Available: https://www.michigan.gov/mdhhs/0,5885,7-339-71551_ 5460 99929---,00.html [Accessed 31 Dec 2020].

32 Messika J, Ben Ahmed K, Gaudry S, et al. Use of high-flow nasal cannula oxygen therapy in subjects with ARDS: a 1-year observational study. Respir Care 2015;60:162-9 https://pubmedncbi-nlm-nih-gov.proxy.lib.wayne.edu/25371400/ doi:10.4187/ respcare. 03423

33 Roca O, Caralt B, Messika J, et al. An index combining respiratory rate and oxygenation to predict outcome of nasal high-flow therapy.
Am J Respir Crit Care Med 2019;199:1368-76 https://pubmed-ncbinlm-nih-gov.proxy.lib.wayne.edu/30576221/

34 Yang X, Yu Y, Xu J, et al. Clinical course and outcomes of critically ill patients with SARS-CoV-2 pneumonia in Wuhan, China: a singlecentered, retrospective, observational study. Lancet Respir Med 2020;8:475-81 https://pubmed-ncbi-nlm-nih-gov.proxy.lib.wayne. edu/32105632/ doi:10.1016/S2213-2600(20)30079-5

35 Wu C, Chen X, Cai Y, et al. Risk factors associated with acute respiratory distress syndrome and death in patients with coronavirus disease 2019 pneumonia in Wuhan, China. JAMA Intern Med 2020;180:934-43 https://pubmed-ncbinlm-nih-gov.proxy.lib.wayne.edu/32167524/ doi:10.1001/ jamainternmed.2020.0994

36 Demoule A, Vieillard Baron A, Darmon M, et al. High-flow nasal cannula in critically III patients with severe COVID-19. Am J Respir Crit Care Med 2020;202:1039-42 https://pubmed-ncbi-nlm-nih-gov. proxy.lib.wayne.edu/32758000/

37 Azoulay E, Lemiale V, Mokart D, et al. Effect of high-flow nasal oxygen vs standard oxygen on 28-day mortality in immunocompromised patients with acute respiratory failure: the high randomized clinical trial. JAMA 2018;320:2099-107 https://pubmedncbi-nlm-nih-gov.proxy.lib.wayne.edu/30357270/

38 Copin M-C, Parmentier E, Duburcq T, et al. Time to consider histologic pattern of lung injury to treat critically ill patients with COVID-19 infection. Intensive Care Med 2020;46:1124-6 https:// pubmed-ncbi-nlm-nih-gov.proxy.lib.wayne.edu/32328726/

39 Lax SF, Skok K, Zechner P. Pulmonary arterial thrombosisarterial thrombosis in COVID-19 with fatal outcomewith fatal outcome : results from a prospective, single-center, clinicopathologic case seriesresults from a prospective, single-center, clinicopathologic case series. Ann Intern Med 2020;173:350-61 https://pubmedncbi-nlm-nih-gov.proxy.lib.wayne.edu/32422076/ doi:10.7326/ M20-2566

40 Puelles VG, Lütgehetmann M, Lindenmeyer MT, et al. Multiorgan and renal tropism of SARS-CoV-2. N Engl J Med 2020;383:590-2 https://pubmed-ncbi-nlm-nih-gov.proxy.lib.wayne.edu/32402155/ doi:10.1056/NEJMc2011400

41 Kang BJ, Koh Y, Lim C-M, et al. Failure of high-flow nasal cannula therapy may delay intubation and increase mortality. Intensive Care Med 2015;41:623-32 https://pubmed-ncbi-nlm-nih-gov.proxy.lib. wayne.edu/25691263/ doi:10.1007/s00134-015-3693-5

42 Hill NS, Ruthazer R. Predicting outcomes of high-flow nasal cannula for acute respiratory distress syndrome. An index that roX. Am $J$ Respir Crit Care Med 2019;199:1300-2 www.atsjournals.org doi:10.1164/rccm.201901-0079ED 